\title{
Exploring the impact of E-business adoption on logistics processes: empirical evidence from the food industry
}

\author{
A. MATOPOULOS, M. VLACHOPOULOU and V. MANTHOU \\ Department of Applied Informatics, University of Macedonia, \\ 156 Egnatia st., 54006, Thessaloniki, Greece, Phone: \\ +302310891728 - Fax: +302310891804
}

\begin{abstract}
The objectives of the research were to identify factors that influence e-business adoption and its impact on logistics processes in the Greek food industry. Drawing on existing research a conceptual framework and propositions were developed and six in depth case studies were carried out. In the framework, three major categories of influencing factors were distinguished: intra-enterprise, sector and supply chain factors. Findings suggest that e-business adoption is more affected by supply chain and sector factors, rather than intraenterprise factors. Regarding the impact of e-business on logistics process it seems that it is affected by the frequency of its use and it is greater in processes occurring at the company-customer interface. Finally, e-business impact is more related to the dimensions of time and quality, rather than cost improvements.
\end{abstract}

Keywords: e-business impact, logistics, food industry

To cite this Article: Matopoulos, A., Vlachopoulou, M. and Manthou, V. (2007) 'Exploring the impact of ebusiness adoption on logistics processes: empirical evidence from the food industry', International Journal of Logistics Research and Applications, 10:2, 109 122 


\section{Introduction}

E-business includes a number of applications that vary in complexity and could be defined as the use of the Internet or any other electronic medium for the execution of transactions, the support of business processes and the improvement of collaboration opportunities among entities (Brown and Lockett, 2004). Despite the fact that the role and the potential impact of e-business adoption on companies have received attention in the literature, many companies are struggling with the question of how e-business impacts their supply chain and logistics processes (Cross, 2000; Ferrari, 2000).

The general scope of this paper is therefore to explore the impact of ebusiness adoption on logistics processes but in a specific industry, since different industries present different characteristics which complicate the analysis (Auramo, 2002). In particular, this paper focuses on the food industry, which is a very dynamic and competitive one and moreover, is of great importance for the Greek, as well as the European economy. Therefore, it is essential to identify whether or not and in what way the adoption of e-business will benefit the adopters. The aim of the paper is to generate understanding of the range of factors that affect e-business adoption in the food industry, and in particular to explore the reasons for different levels perceived of e-business impact. The paper initially presents a conceptual framework, which takes into consideration both firm and non-firm related factors that is believed to affect e-business adoption. Finally, emphasis on the impact of e-business on logistics processes is given and links between the factors affecting e-business adoption and the impact of e-business are explored. The paper is organized as follows: initially a review of the literature regarding e-business adoption and ebusiness impact is provided which is followed by the research model and the research methodology. Next, a presentation of the findings follows along with conclusions, research implications and limitations. 


\section{Insights from the Greek food supply chain: facts, key trends and challenges}

The food industry is one of the most dynamic sectors in the Greek economy, constituting the top manufacturing activity, placed higher than the petroleum and the non metallic minerals sector (CIAA, 2005). Historically, the Greek food sector was characterized by the existence of small-medium size companies (SME's), however after 1990's, large domestic companies were created and multinational companies have also entered the market. The sector accounts for about $6.5 \%$ of GDP, employs $25 \%$ of the total workforce on a full or part-time basis and grows with a high development ratio which reaches $5 \%$ on average each year (Hotel and Restaurant, 2004; National Statistical Service of Greece, 2005).

The Greek food supply chain is characterized by the existence of significant differences. At the food processor level, nearly 1000 companies exist and most of them are mainly small family based companies (CIAA, 2003; Greek General Secretary of Trade, 2005). Only lately a number of mergers and acquisitions has occurred but not as intense as in the retailer sector. At the wholesaler level most companies are also small family based companies and concentration of the market is relatively low. As a result, the role and the power of these companies have been diminished in favour of retailers. At the retailer level, the appearance of new multinational players in the early 1990's increased the level of competition fostering domestic retailers to accelerate their growth through acquisition of smaller ones, and entry to new markets (Doukidis, 2004). Retailers, both domestic and multinational have nowadays become the most powerful players in the sector exercising their power to every other entity in the food supply chain. The entrance of the new multinational retailers has also influenced the structure of the logistics systems of companies. Prior to the entrance of multinational companies, the availability of warehouse sites and third-party companies was limited and the implementation of logistics practices by domestic retailers was very weak (Bourlakis and Bourlakis, 2001). However, the establishment of more complex network of stores across Greece encouraged domestic 
retailers to rethink and re-evaluate their logistics strategy by developing strategic partnerships or by outsourcing logistics activities to third parties. In particular, emphasis was placed on ordering and product promotion, while in the area of collaborative demand forecasting and inventory management major weaknesses still exist (IEIR, 2005).

\section{Analyzing e-business adoption and impact}

E-business applications present similarities to other technologies, considering adoption in the sense that companies also need to invest capital and labour in order to realize some benefits. As a result, various approaches such as the Technology Acceptance Model (Davis, 1989) and Rogers' (1995) model on the diffusion of innovation could be also used to explain the adoption process. However, despite the similarities, significant differences also exist due to the fact that e-business applications are based on the interaction of more than one company, spanning the boundaries of individual firms. The supply chain instead of the individual firm is the main and optimum field for e-business applications to grow and as a result, emphasis should be given on other factors. For this reason, many authors argue the e-business adoption surveys should use different criteria than those used in other technologies, since those are over simplistic and intra-enterprise, instead of inter-enterprise focused (Culkin and Smith, 2000; Martin and Matlay, 2001). Consequently, in this paper the role of other factors, which are not directly linked to the focal enterprise, such as sector's characteristics and supply chain factors, is taken into consideration.

\subsection{Factors influencing e-business adoption}

The characteristics of each business sector have been shown in the literature to influence e-business adoption (Kwon and Zmud, 1987; Mehrtens et al. 2001; Raymond, 2001), by changing the operational compatibility and the relative advantage of the company adopting ebusiness (Premkumar and Roberts, 1999; Sadowski et al., 2002). The food industry in particular is characterized by two factors that influence ebusiness adoption: competition and the nature of the products. Nowadays 
the sector is more competitive than ever before due to the globalization and deregulation of the markets, the existence of powerful companies and the increased needs of customers for service (Nitchke and O'Keefe, 1997; Folkerts and Koehorst, 1998; Saxowvsky and Duncan, 1998). Companies in an effort to respond to these changes try to improve the effectiveness of their processes by reducing costs and time.

Therefore, e-business has been perceived by many authors as a way to improve the performance of the company in many areas (Tucker and Jones, 2000; Tan, 2001; Lee and Whang, 2002). Regarding the nature of the products, they present a number of unique characteristics related to their perishable nature and seasonality (Den Ouden et al. 1996; Epperson and Estes, 1999). This very nature of products imposes constraints and diminishes the applicability of e-business.

Intra-enterprise factors are related to the specific characteristics of the company, such as the size of the company, the emphasis placed by the management and the human factor. Company's size, which is related to financial and human resources, has been recognized in many different business sectors as a critical factor in the adoption process, (Stokes, 2000; Knight, 2001; Van Beveren and Thomson, 2002). The support and the commitment of top management are also vital and have been identified by many authors (Damanpour, 1991; Henderson et al. 2000). In many cases, particularly when it comes to SME's this factor is equally or even more critical in the adoption decision (Fillis et al. 2003). In addition, the human factor, particularly regarding e-business knowledge and experience is important (Mehrtens et al. 2001).

Finally, supply chain factors refer to the external business environment of the company, including the complexity of the supply chain, the level of collaboration among entities and the nature of the relationship, in terms of power and dependence. The complexity of the supply chain is related to the number of suppliers and customers of the company and their proximity. More complex supply chains are more likely to adopt ebusiness applications and to realise more benefits and greater impact on their logistics processes. Companies that are characterized by close collaboration and increased dependence adopt easier applications such as e-business (Patterson et al. 2003). The pressure from company's 
environment has been shown to affect e-business adoption (Premkumar and Roberts, 1999; Mehrtens et al. 2001; Daniel and Grimshaw, 2002). For example, Wal-Mart, one decade ago demanded from its suppliers to adopt Electronic Data Interchange (EDI) (Premkumar et al. 1997), and currently did the same regarding the Radio Frequency Identification adoption (Wailgum, 2004).

\subsection{E-business impact}

The importance of e-business applications along with their central role in logistics and supply chain management have been recognized and analysed by many authors (Gecowets and Bauer, 2000; Lancioni et al. 2000; Johnson and Classen, 2005). However, what seems to be missing is a more focused study on the impact of e-business on specific processes. So far most of the research (Thompson, 1996; Henderson et al. 2000; Hooker et al. 2001; Johnson, 2001) has been emphasizing on the specific application of e-commerce and on stating the potential benefits arising from its use. In addition, the majority of studies have been carried out in more advance economies and sectors than Greece and the food industry, respectively. Croom (2005), for example examined the impact of e-business on supply chain management in ninety-two companies, but most of these companies were multinational giants. In Greece, many of these studies were survey based. For example, Papathanassiou et al. (2003) and Salampasis et al. (2003) in their studies focused mainly on e-commerce and Internet use, without exploring the issue of adoption and also without linking the adoption with the respective impact on the company.

This paper relates the impact of e-business adoption to logistics processes, such as customer service, ordering (order-taking and processing) and procurement. In order to do this a combination of financial and non financial factors, such as cost, speed and quality, were selected. The use of both financial and non-financial measures will provide a more complete view (Eccles, 1998; Neely, 1999; Gunasekaran et al. 2001). Cost is one of the most useful and fundamental factors (Chow et al. 1994; Ghalayini et al. 1997). Time is also a very critical factor 
particularly in the context of the food industry (Kearney, 1999; Logistics Europe, 1998; Medori and Steeple, 2000). Quality is a very broad concept which encapsulates a number of dimensions such as: reliability, flexibility, level of service, responsiveness, security (Crosby, 1979; Parasuraman et al. 1998). In this paper, reliability and flexibility are further considered, due to their importance for logistics processes (Mason-Jones et al. 1999). Overall, the use of e-business in logistics processes is believed to greatly affect cost, time and quality factors (Zeng and Pathak, 2003; Rahman, 2004).

\section{Conceptual framework}

One of the fundamental ideas behind this framework is that e-business adoption and its impact is not an exclusively intra-enterprise issue, due to the interactive nature of e-business applications. Under this aspect, three major categories of influencing factors were distinguished: intraenterprise, sector and supply chain factors. The conceptual framework and propositions for subsequent testing are described below and are deduced from empirical researches from literatures (Kwon and Zmud, 1987; Culkin and Smith, 2000; Martin and Matlay, 2001; Patterson et al. 2003).

Figure 1

In addition, in this framework e-business adoption is not merely about having Internet access or having a website, but goes beyond the observation of these applications and links them with the impact that create to the logistics processes of the firm. As a result, the conceptual framework in this article consists of three constructs: factors affecting ebusiness adoption, e-business adoption and e-business impact. The propositions developed are the following:

P1a. The increased competition in the sector influences e-business adoption by companies

$\mathrm{P} 1 \mathrm{~b}$. The nature of products, impinges e-business adoption

P2a. E-business adoption is limited, when there is lack of financial resources 
P2b. E-business adoption is affected by company's management perspectives and attitudes

P2c. E-business adoption is limited by the lack of knowledge and skills from personnel

P3a. E-business adoption is greater, when the complexity of the supply chain increases

P3b. E-business adoption is greater when the level of collaboration among companies increases

P3c. E-business adoption is enhanced, when the company experiences/exercises pressure from/on companies

$\mathrm{P} 4 \mathrm{a}$. The impact of e-business on logistics processes is not dependent on the complexity of the e-business application adopted, but on the frequency of its use.

P4b. The impact of e-business is greater for those logistics processes, conducted at the company- customer interface, rather than at the company-supplier interface.

P4c. The use of e-business in logistics processes will have significant impact on cost, time and quality attributes of the processes

\section{Methodology}

Case study research and in particular multi-case studies was preferred, since it enables a more descriptive and exploratory approach allowing for more rich insights into the research object (Yin, 1994; Miles and Huberman, 1994). The research enters essentially into three major areas, namely: information and communication technologies (where e-business in included), logistics and the food industry. Case study research has been lately recognised as an increasingly important type of research in each one of these three areas, since traditional research strategies have been often proved to be limited in their applicability and scope (Mentzer and Kahn, 1995; Meredith, 1998; Sterns et al. 1998; Myers and Avison, 2002; Naslund, 2002; Mangan et al. 2004). 


\subsection{Case selection and description}

Six companies from the food sector were selected for case study research identified based on contacts from the university and industry associations. The availability of access was also an important factor, particularly in the case of Greece, where companies are often hesitant to participate in studies. Of course, the sample does not enable any type of statistical generalizations to be made for the food industry. The companies agreed to take part in the research provided that confidentiality was assured. These companies, together with their general characteristics are presented below.

Table 1

Firms are called firm A to $F$, as indicated. Firms A and B, are two of the biggest retailers in Greece. In particular, firm $A$ is the Greek branch of a multinational retailer, while firm B is a domestic one. Firm C, is the Greek part of a multinational dairy company, while firm $D$ is a domestic company that is supplying food products (burgers, salads etc) to the biggest fast food chain restaurant in Greece. Finally, firms $E$ and $F$ operate in the fruit canning industry.

\subsection{Data collection}

Semi-structured in depth interviews with different managers from the companies were the main research method used. In order to ensure the validity of this study, suggestions from previous studies were followed (Miles and Huberman, 1994; Yin, 1994). A case study protocol was designed and used to guide the structured interviews and data collection (Yin, 1994). The interviews were based on the research model. A pilot study was also conducted to review the research propositions improved the conceptual understanding of the research issues. On the whole, sixteen interviews were carried out and each one took 1-1.5 hours. All interviews were tape recorded after taking the consent of the interviewee and prior to each interview, the research agenda was explained. Data collection included various sources such as, interviews, direct observation 
(of the e-business applications on operation), and documentation, in an effort to enhance both the reliability and validity of this study. While most of the data were qualitative in nature, quantitative data (e.g. cost and time improvements, errors reduction) based on managers' assessment were also collected to verify the findings. For this kind of data a five-point perceptual interval scale ranging from 1 (non-it means there is no impact on logistics processes) to 5 (extensive- it means there is an extensive impact) was used, to allow respondents to report the perceived impact of e-business on logistics processes.

\section{Empirical evidence}

\subsection{Sector's factors influencing adoption}

In terms of sector's competition, only interviewees from firms A, B, E and $F$ declared that competition pressures are an influencing factor. This is probably due to the fact that these companies, in comparison to $C$ and $D$ are more competition driven. Indeed, the retail sector where firm A and B operate is one of the most competitive food sub-sectors as a result of diminishing profit margins as well as the entrance of hard discount retailers (Doukidis, 2004; IEIR, 2005). In addition, firms $E$ and $F$ due their export orientation are more sensitive to competition signals. However, what is also interesting is that firms $A$ and $B$ emphasized on cost-based competition. In fact, manager from firm A stated that: "in our company we perceive technology as the cornerstone for cost reductions". This is quite interesting aspect of the Greek food industry in particular, in comparison to the European, where time-compression and reduction of order cycle time in the last decade is becoming one of the important logistics strategies for companies (Logistics Europe 1998; Kearney, 1999).

Regarding the nature of food products, it seems that is one of the most constraining factors considering e-business adoption, supporting the proposition $\mathrm{P} 1 \mathrm{~b}$. Indeed, in all cases respondents stated that the perishable nature of the product, along with the specific requirements and its seasonality deteriorated e-business adoption to simple applications. For example, the manager from firm $\mathrm{F}$ stated that: "not all applications fit 
to our business; more applicable seem to be those related to information exchanges and not more complex applications-even if we had these applications we wouldn't be able to benefit". An interesting aspect is the pressure that firm E put on its customers to use the web-based ordering application. This is one of the rare cases, since firm $E$ is a small company in comparison to its customers. Firm E, is a canned fruit company that for the last seven years is the major supplier of canned peaches for three of the top five British retailers. In an effort to innovate and to improve its operations, it developed an online ordering system to facilitate ordering from abroad. However, quite surprisingly retailers did not prefer it. Instead, it was preferred by the retailer to visit the company and to control the infrastructure and standards and protocols (BRC, EurepGap) followed.

\subsection{Intra-enterprise factors influencing adoption}

Lack of financial resources was not stated by interviewees as a significant constraint to e-business adoption. It is quite interesting the view of one manager from firm E, who argued that: "adopting e-business nowadays is not really a matter of money, time or personnel. These factors are just an excuse from small companies' part in an effort to avoid changing their way of doing business". Empirical results show that the case companies' decision to invest on e-business is not prevented by the cost of investment, even in the smaller companies of the sample and this concurs with a previous survey conducted in Greece by Manthou et al. (2005). Therefore, the proposition P2a was not supported by these case studies. In terms of management emphasis and attitudes it was clear that top managers had a central role in the adoption process. Particularly, in smaller firms (firm $E$ and firm $F$ ), managers had a leading role in the decision to adopt e-business. Therefore, the proposition $\mathrm{P} 2 \mathrm{~b}$ is supported. Finally, regarding human resources none company reported problems, as a result of users lacking skills to properly use e-business applications. Therefore, the proposition P2c was not supported. 


\subsection{Supply chain factors influencing adoption}

The complexity of the supply chain was stated by firms A and B, as a significant reason to adopt e-business applications. Each retailer has a supplier base consisting of approximately 200 suppliers and a customer base (shop) of 360 shops (firm A) and 170 shops (firm B). In that aspect, synchronization requirements are greater, than in firms $C, D, E$ and $F$ where they have a quite simple supply chain structure with limited number of suppliers and customers. Therefore, the proposition P3a is supported.

All companies in the case studies agreed that increased levels of collaboration have a positive effect on e-business adoption supporting the proposition P3b. In all cases, except in firms A and B, e-business adoption was limited to simple applications due to the nature of business relationships which was characterised by limited trust, lack of goals mutuality, of resource sharing and independent autonomy. On the contrary, in the case of the retailers $\mathrm{A}$ and $\mathrm{B}$, a more complex e-business application (EDI) was going to be implemented in the relationship with one key manufacturer and one key wholesaler, respectively.

Regarding business pressure from companies, it seems that is one of the most important factors that affect e-business adoption, supporting thus the proposition P3c. "If companies ask for it, we are going to make it" was the statement of one manager from firm $D$. All the companies agreed that business pressure particularly, when it comes to key suppliers or customers results in increased adoption efforts. Firms A and B for example, have forced some suppliers to change their processes and to use simple e-business applications. Surprisingly, a few suppliers refused to go electronically and as a result, the company refused to do business with them. Firms C, D, E and F analogously declared that to a great extent they follow the suggestions of their major customers.

\subsection{Factors influencing the impact of e-business}

In the assessment of the impact of e-business on logistics processes, it was revealed that all case companies realized some impact. In particular, this impact was higher in the case of firms A and B (4.0 and 3.8 respectively), moderate in the case of firms $C$ and $D$ (2.85 and 3 
respectively) and limited in the case of firms $E$ and $F$ ( 2 and 1.8 respectively). This is surprising, since all companies are using more or less the same e-business applications (e-mail, intranet and extranet). However, what is different in these companies is the frequency and width of use. Firms $A$ and $B$ for example in comparison to others, use ebusiness application with all of its customers and suppliers frequently, creating thus, a critical mass of transactions necessary to realize the impact. On the contrary, firms $E$ and $F$, due to the seasonality of the product and production processes, have a rather rare use of e-business applications. Therefore, the proposition $\mathrm{P} 4 \mathrm{a}$ is supported.

Concerning the imbalanced impact of e-business on specific logistics processes, results demonstrate that on average the impact of e-business on customer service and ordering is greater than in procurement. This is explained given the fact that both customer service and ordering occur at the company- customer interface, where customers are big companies with frequent use of e-business applications. Thus, the proposition P4b is supported. Regarding, the dimensions of performance that are affected by the use of e-business, from all six case studies it is revealed that the dimension of cost is perceived by respondents as the less significant, in comparison to time and quality. As a result, proposition P4C is not supported. In tables below a summarized verification of propositions is presented.

\section{Table 2}

Table 3

\section{Conclusions and managerial implications}

This paper has discussed e-business adoption and its impact on logistics processes in the context of the food sector, where adoption rates are low. Factors associated to e-business adoption were identified from the literature, whereas factors explaining the impact of e-business were proposed. In total, eleven propositions were developed with the aim of identifying the factors influencing e-business adoption and its impact on logistics processes. 
The factors that influence e-business adoption are spanning the boundaries of the firm. In particular, sector's factors, as well as supply chain factors proved to play a role in the decision of companies to adopt or not e-business applications. Much of the research so far, was focusing on intra-enterprise factors in an effort to explain e-business adoption. In this research, traditional intra-enterprise factors such as financial and human resources availability, although important were not stated as significant constraints to e-business adoption.

The findings concur also with the findings of Caldeira and Ward (2003) regarding the adoption of IS/IT systems in Portuguese small-medium sized enterprises. The very nature of food products adds significant difficulties in adopting e-business applications, due to the need to physically control prior transacting, raising the issue of trust also. Firm $\mathrm{E}$ for example, developed a web-ordering platform, but some time had to quit, since efforts to convince its major customers proved futile. From the research, supply chain factors proved to be a significant constraint to ebusiness adoption. It appears that more complex supply chains are more likely to adopt e-business applications. In addition, as expected, extensive business pressure and increased level of collaboration, are both influencing significantly e-business adoption. Managers should therefore be prepared to put emphasis on developing their relationships with their suppliers/customers, in an effort to do common e-business investments, and moreover should aim at increasing the commitment of their companies in using these applications.

Regarding e-business impact on logistics process it was revealed that ebusiness impact on logistics processes is depended on the frequency of its use. Companies that demonstrated increased use of e-business applications reported the major impact, despite the fact that they were using similar applications to the other case companies. Finally, an important aspect from the research is the fact the impact of e-business on logistics processes mainly refers to time reductions and quality improvements, rather than cost reductions as reported by many authors (Croom, 2000; De Boer et al. 2002). As a result, managers prior investing in e-business applications should be in position to estimate the expected 
results, since the investment on technology is by no means assuring successful business outcomes.

Drawing on the results of this study the authors believe that food companies in Greece have not adopted more complicated e-business applications, since nobody ask for it so far. Only companies that are competition-sensitive seem to react to the developments. In a recent letter sent by firm $A$, in the entire supplier base, in an effort to prepare EDI adoption, only five percent of the suppliers responded. From the studies it is clear that the adoption of these applications is not exclusively a matter of resources. Food companies in Greece, even large ones still have an intra-organisational viewpoint of e-business, making it difficult to use applications that span organisational boundaries.

This research has several constraints that limited the applicability of the case study results. These constraints are related to the intrinsic weakness of the case study method, which limits the ability to generalise the findings and conclusions. However, the explanations derived can be helpful to other researchers involved in the understanding of the adoption of ebusiness and its impact. Results obtained may be also relevant to other countries and other national context particularly as regard as the role of the proposed factors affecting e-business adoption. In the case of national environments presenting differences in their logistics systems it is expected that in countries where logistics systems are more evolved, companies will be able to realize more benefits.

Future research should emphasize on studying the impact of e-business adoption on other logistic processes. In addition, quantitative research should also be conducted using a large sample of companies in order to be able to generalise results. A longitudinal study would also be of a great interest in order to control the model in the future and to identify whether or not and in what way the role of the proposed factors and the impact of e-business have altered. 


\section{References}

Auramo, J., Aminoff, A. and Punakivi, M., Research agenda for e-business logistics based on professional opinions, Int. J. of Physic. Distrib. and Logistics Mgmnt, 2002, 32(7), 513-531.

Brown, D.H. and Locket, N., Potential of critical e-applications for engaging SMEs in e-business: a provider perspective, Eur. J. of Inf. Systems, 2004, 13, 21-34.

Bourlakis, M.A. and Bourlakis, C.A., Deliberate and emergent logistics strategies in food retailing: a case study of the Greek multiple food retail sector. Supply Chain Mgmnt, 2001, 6, 189-200.

Caldeira, M. M. and Ward, J. M., Using resource-based theory to interpret the successful adoption and use of information systems and technology in manufacturing small and medium-sized enterprises, Eur. J. of Inf. Systems, 2003, 12, 127-141.

Chow, G., Heavers, T.D. and Henriksson, L.E., Logistics performance: definition and measurement, Int. J. of Physic. Distrib. and Logistics Mgmnt, 1994, 24(1), 1728.

CIAA, The European food and drink industry and the EU common agricultural policy, 2003, Available online at: http://www.ciaa.be/Key\%20facts\%20\&\%20fig-UK.pdf (accessed 05/11/2003).

CIAA, Data and trends in the European food and drink industry, 2005, Available on line at: http://www.ciaa.be/Data \& Trends .pdf (accessed 05/02/2007).

Croom, S.R., The impact of Web-based procurement on the management of operating resources, J. of Supply Chain Mgmnt, 2000, 36(1), 4-13.

Croom, S.R., The impact of e-business on supply chain management, Int. J. of Oper. and Product. Mgmnt, 2005, 25(1), 55-73.

Crosby, P.B., Quality is free, 1979 (McGraw-Hill: New York).

Cross, G.J., How e-business is transforming supply chain management, The J. of Business Strategy, 2000, 21(2), 36-39.

Culkin N. and Smith, D., An emotional business: a guide to understanding the motivations of small business decision takers, Qualit. Market Research: An Int. J., 2000, 3(3), 145-157.

Damanpour, F., Organizational innovation: a meta-analysis of effects of determinants and moderators, Academy of Mgmnt J., 1991, 34(3), 555-590.

Daniel, E.M. and Grimshaw, D.J., An exploratory comparison of electronic commerce adoption in large and small enterprises, J. of Inf. Tech.., 2002, 17, 133147.

Davis, F.D., Perceived usefulness, perceived ease of use, and user acceptance of information technology, MIS Quarterly, 1989, 13(3), 319-340.

DeBoer, L., Harink, J. and Heijboer, G., A conceptual model for assessing the impact of electronic procurement, Eur. J. of Purch. and Supply Mgmnt, 2002, 8(1), 25-33. 
Den Ouden, M., Dijkhuisen, A. A., Huirne, R. B. and Zuurbier, P. J., Vertical cooperation in agricultural production-marketing chains with special reference to product differentiation in pork, Agribusiness, 1996, 12(3), 277-290.

Doukidis, G., The contribution and competitiveness of food retailing, Eltrun Working Paper Series, WP 2004-005, 2004 Athens University of Economics and Business (in Greek).

Eccles, R., The performance measurement manifesto, Harvard Business Review on Measuring Corporate Performance, pp. 25-46, 1998 (Harvard Business School Press: Boston, MA),

Epperson, J.E. and Estes, E.A. Fruit and vegetable supply chain management, innovations and competitiveness, J. of Food Distrib. Research, 1999, November, 38-42.

Ferrari, R., White paper frontline supply chain managers struggle with e-business, September, 2000 (Richmond Events and AMR Research White Paper: New York).

Fillis, I., Johansson, U. and Wagner, B.A., A conceptualization of the opportunities and barriers to e-business development in the smaller firm, J. of Small Business and Enterprise Development, 2003, 10(3), 336-344.

Folkerts, $H$. and Koehorst, $H$., Challenges in international food supply chains: vertical co-ordination in the European agribusiness and food industries, Brit. Food J., 1998, 100, 385-388.

Gecowets, G. and Bauer, M., The effect of the Internet on supply chain and logistics, World Trade, 2000, 13(9), 71-80.

Greek General Secretary of Trade, Newsletter, March 2005, Available online at: http://www.gge.gr/7/sub.asp?774 (accessed 17/06/2005).

Ghalayini, A., Noble, J. and Crowe, T., An integrated dynamic performance measurement system for improving manufacturing competitiveness, Int. J. of Product. Economics, 1997, 48, 207-225.

Gunasekaran, A., Patel, C. and Tirtiroglou, E., Performance measures and metrics in a supply chain environment, Int. J. of Oper. and Product. Mgmnt, 2001, 21(1/2), 71-87.

Henderson, J., Dooley, F. and Akridge, J. Adoption of e-commerce strategies for agribusiness firms, In Proceedings of the American Agricultural Economics Association Annual Meeting, 2000.

Hooker, N.H., Heilig, J. and Ernst, S., What is unique about e-agribusiness? In Proceedings of the IAMA World Food and Agribusiness Symposium, 2001.

Hotel \& Restaurant, Food industry in new dynamic phase. 2004, Available online at: http://www.hotelrestaurant.gr/online/article.asp?returnPage=SECTION\&group=3\&section= 10\&articleid=1358 (accessed 19/03/2004)..

Johnson, D., Dot-coms and agriculture: what have we learned?, Canadian Society of Extension, 2001.

Johnson, P.F. and Classen, R. D., E-procurement, MIT Sloan Management Review, 2005, 46(2), 7-10. 
IEIR, The Greek food and drink industry, Annual Report, 2005, Institute of Economic and Industrial Research (in Greek).

Kearney, A.T., Insight to impact: results of the fourth quinquennial European logistics study, 1999, European Logistics Association, Brussels.

Knight, G., Entrepreneurship and strategy in the international SME's, J. of Int. Mgmnt, 2001, 7, 155-171.

Kwon, T.H. and Zmud, R.W., Unifying the fragmented models of information systems implementation, In Critical Issues in Information Systems Research edited by Boland, R.J., Hirschheim, R.A., pp. 247- 252, 1987 (John Wiley: New York).

Lancioni, R., Smith, M., and Oliva, T., The role of the Internet in supply chain management, Industrial Marketing Mgmnt, 2000, 29, 45-56.

Lee, H.L. and Whang, S., Supply Chain Integration over the Internet, In Supply Chain Management: Models, Applications and Research Directions, edited by Geunes, J., Pardalos, P. and Romeijn, E. pp. 3-17, 2002 (Kluwer Publishers: Dordrecht, The Netherlands)

Logistics Europe, Patterns of change: European logistics services are improving, Logistics Europe, 1998, 6(4).

Mangan, J., Lalwani, C. and Gardner, B. Combining quantitative and qualitative methodologies in logistics research, Int. J. of Physic. Distrib. and Logistics Mgmnt, 2004, 34(7), 565-578.

Manthou, V., Matopoulos, A. and Vlachopoulou, M., Internet-based applications in the agri-food supply chain: a survey on the Greek canning sector, J. of Food Engineering, 2005, 70, 447-454.

Martin, L.M. and Matlay H., Blanket approaches to promoting ICT in small firms: some lessons from the DTI ladder adoption model in the UK, Internet Research: Electr. Networking Applic. and Policy, 2001, 11(5), $399-410$.

Mason-Jones, R. and Towill, D. R., Using the information decoupling point to improve supply chain performance, Int. J. of Logistics Mgmnt, 1999, 10(2), 13-26.

Medori, D. and Steeple, D., A framework for auditing and enhancing performance measurement systems, Int. J. of Oper. and Product. Mgmnt, 2000, 20(5), 520-533.

Mehrtens, J., Cragg, P.B., and Mills, A.M., A model of Internet adoption by SME's, Inform. \& Mgmnt, 2001, 39(3), 165-176.

Mentzer, J. and Kahn, K., A framework of logistics research, J. of Bus. Logistics, 1995, 6(1), 231-250.

Meredith, J., Building operations management theory through case and field research, J. of Oper. Mgmnt, 1998, 16, 441- 454.

Myers, M.D. and Avison, D.E., Qualitative Research in Information Systems: A Reader, 2002 (Sage Publications: London).

National Statistical Service of Greece, Industrial production index. Press Release, December 2005.

Neely, A., Measuring Business Performance, 1999, (The Economist Books). 
Naslund, D., Logistics needs qualitative research: especially action research, Int. J. of Physic. Distrib. and Logistics Mgmnt, 2002, 32(5), 321-338.

Nitchke, T. and O'Keeffe, M., Managing the linkage with primary producers: experiences in the Australian grain industry, Supply Chain Mgmnt: An Int. J., 1997, 2(1), 4-6.

O'Keeffe, M. and Mc Eachem, S., The perishable food industry: ripe for e-commerce, 2001 Available online at: http://www.internetcapital.com/network/progress/pdf/agribuys-Ripe2.pdf (accessed 05/06/2004).

Papathanassiou, B., Kardaras, D. and Arkoumani, B., Management context and impact of e-commerce in the development of Greek food industries, Logistics Inf. Mgmnt, 2003, 16(2), 134-144.

Parasuraman, A., Zeitham, V. and Berry, L., SERVQUAL: a multiple item scale for measuring customer perception of service quality, J. of Retailing, 1998, 64(1), 1240.

Patterson, K.A., Grimm, C.M. and Corsi, T.M., Adopting new technologies for supply chain management, Transp. Research Part E, 2003, 39, 95-121.

Premkumar, G., Ramamurthy, K. and Crum, M.R., Determinants of EDI adoption in the transportation industry, Eur. J. of Inf. Systems, 1997, 6(2), 107-121.

Premkumar, G. and Roberts, M., Adoption of new information technologies in rural small businesses, Omega, The Int. J. of Mgmnt Science, 1999, 27(4), 467-484.

Rahman, Z., Use of the Internet in supply chain management, Industrial Mgmnt and Data Systems, 2004, 104(1), 31-41.

Rogers, E. M., Diffusion of Innovations, 1995 (The Free Press: New York).

Sadowski, B. M., Maitland C. and van Dongen, J., Strategic Use of the Internet by Small- and Medium- Sized Enterprises: An Exploratory Study, Inf. Economics and Policy, 2002, 14, 75-93.

Salampasis, M., Batzios, C., Samathrakis, V., Adroulidakis S. and Adroulidaki, M. Use and impact of the Internet in the Greek agricultural sector, In Proceedings of the $4^{\text {th }}$ EFITA Conference, 2003.

Saxowvsky, D. and Duncan, M., Understanding agriculture's transition into the 21st century: challenges, opportunities, consequences and alternatives, Report 181, Department of Agricultural Economics, North Dakota State University, 1998.

Sterns, J., Schweikhardt, D. and Peterson, C., Using case studies as an approach for conducting agribusiness research, Int. Food and Agribusiness Mgmnt Review, 1998, 1(3), 311-327.

Stokes, D., Marketing and the small firm, In Enterprise and Small Business: Principles, Practice and Policy, edited by Carter, S. and Jones Evens, D. (Eds.), pp. 354-383, 2000 (Pearson Education Ltd, London).

Tan, K.C., A framework of supply chain management literature, Eur. J. of Purch. and Supply Mgmnt, 2001, 7(1), 39-48. 
Thompson, S., Potential effects of information technologies on the economic performance of agricultural and food markets, In Proceedings of the Symposium on Global Restructuring of Agro-Food Markets, 1996.

Tucker, D. and Jones, L., Leveraging the power of the Internet for optimal supplier sourcing, Int. J. of Physic. Distrib. and Logistics Mgmnt, 2000, 30(3-4), 255-267.

USDA, Retail food sector in Greece., GAIN Report, GR-3024, 2003, Available online at: http://uww.fas.usda.gov/gainfiles/200312/146085299.pdf (accessed 08/08/2003).

Van Beveren, J. and Thomson, H., The use of electronic commerce by SME's in Victoria, Australia, J. of Small Bus. Mgmnt, 2000, 40(3), 250-253.

Wailgum, T., Tag you are late, CIO magazine, November Issue, 2004 Available online at: http://www.cio.com/archive/111504/rfid.htm (accessed 20/12/2004).

Yen, B.P. and Ng, E.O., The migration of electronic commerce, Mgmnt Decision, 2003, 41(7), 656-665.

Zeng, A.Z. and Pathak, B.K., Achieving information integration in supply chain management through B2B e-hubs: concept and analyses, Industrial Mgmnt and Data Systems, 2003,103(9), 657-665.

\section{Biographies}

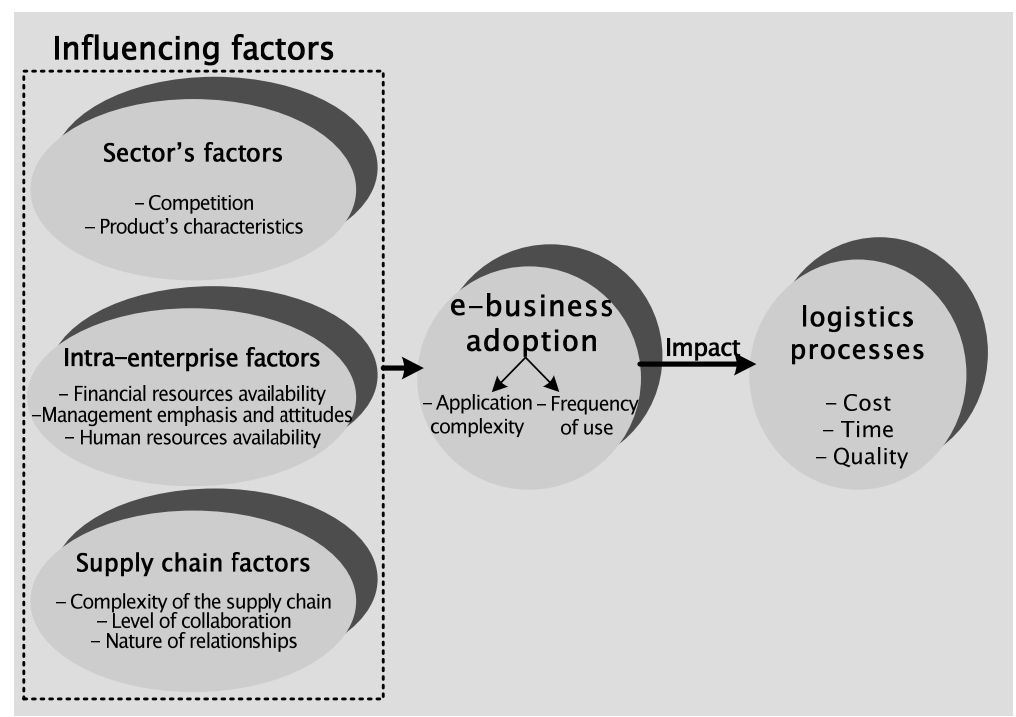

Figure 1 - Research model

Table 1 - Characteristics of the firms involved in case study research

\begin{tabular}{llllll}
\hline Firm & Sub-sector & $\begin{array}{l}\text { Turnover } \\
\text { (million } € \text { ) }\end{array}$ & $\begin{array}{l}\text { Number of } \\
\text { employees }\end{array}$ & $\begin{array}{l}\text { Number of } \\
\text { interviewees }\end{array}$ & Interviewees \\
\hline A & Retailer & 400 & 2500 & 2 & $\begin{array}{l}\text { Logistics } \\
\text { manager } \\
\text { IT manager }\end{array}$ \\
\hline
\end{tabular}




\begin{tabular}{|c|c|c|c|c|c|}
\hline$B$ & Retailer & 450 & 2500 & 3 & $\begin{array}{l}\text { Logistics } \\
\text { manager } \\
\text { IT manager } \\
\text { Purchasing } \\
\text { manager }\end{array}$ \\
\hline C & Manufacturer & 425 & 150 & 3 & $\begin{array}{l}\text { Finance } \\
\text { Director } \\
\text { Logistics } \\
\text { Manager } \\
\text { IT manager }\end{array}$ \\
\hline D & Manufacturer & 75 & 380 & 3 & $\begin{array}{l}\text { Logistics } \\
\text { director } \\
\text { Purchasing } \\
\text { manager } \\
\text { IT manager }\end{array}$ \\
\hline$E$ & Manufacturer & 22 & 36 & 3 & $\begin{array}{l}\text { CEO } \\
\text { Finance } \\
\text { manager } \\
\text { IT manager }\end{array}$ \\
\hline $\mathrm{F}$ & Manufacturer & 18 & 32 & 2 & $\begin{array}{l}\text { CEO } \\
\text { Finance } \\
\text { director }\end{array}$ \\
\hline
\end{tabular}

Table 2 -Summary of verification of propositions

\begin{tabular}{|c|c|c|c|c|c|c|}
\hline Propositions & Firm A & Firm B & Firm C & Firm D & Firm E & Firm F \\
\hline 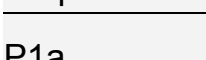 & Supported & Supported & Not & Not & Supported & Supported \\
\hline rla & \multicolumn{6}{|c|}{ Supported Supported } \\
\hline $\mathrm{P} 1 \mathrm{~b}$ & \multicolumn{6}{|c|}{ Supported Supported Supported Supported Su } \\
\hline & Not & Not & Not & Not & Not & Not \\
\hline P2a & \multicolumn{6}{|c|}{ Supported Supported Supported Supported Supported Supported } \\
\hline $\mathrm{P} 2 \mathrm{~b}$ & \multicolumn{6}{|c|}{ Supported Supported Supported Supported Suppc } \\
\hline & Not & Not & Not & Not & Not & Not \\
\hline ZC & \multicolumn{6}{|c|}{ Supported Supported Sup } \\
\hline P3a & \multicolumn{6}{|c|}{ Supported Supported Su } \\
\hline $\mathrm{P} 3 \mathrm{~b}$ & \multicolumn{6}{|c|}{ Supported Supported Su } \\
\hline P3c & \multicolumn{6}{|c|}{ Supported Supported Su } \\
\hline P4a & \multicolumn{6}{|c|}{ Supported Supported Supported Su } \\
\hline $\mathrm{P} 4 \mathrm{~b}$ & \multicolumn{6}{|c|}{ Supported Supported Supported Supported Suppo } \\
\hline $\mathrm{P} 1 \mathrm{r}$ & Not & Not & Not & Not & Not & Not \\
\hline $\mathrm{P} 4 \mathrm{C}$ & \multicolumn{6}{|c|}{ Supported Supported Supp } \\
\hline
\end{tabular}

Table $3^{*}$-Impact of e-business on logistics processes 


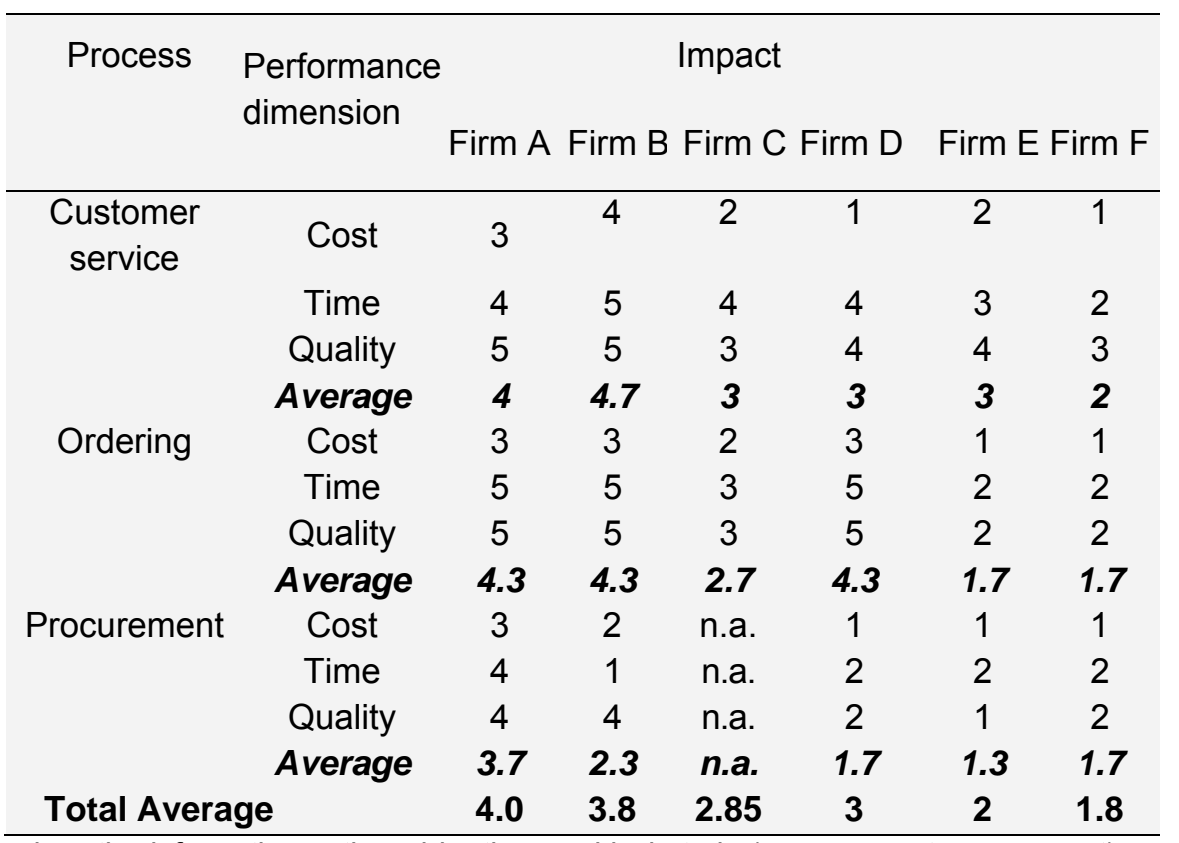

*Based on the information gathered by the empirical study (management assessment), results have been derived from the average of the dimensions of each logistics process. A five-point scale was used ranging from 1 (no impact) to 5 (extensive impact). 